1. BDS, FCPS

Principal,

Bibi Aseefa Dental College,

Larkana, Sindh.

Assistant Professor \&

Head of Department of

Oral and Maxillofacial Surgery,

Bibi Aseefa Dental College,

Larkana, Sindh.

2. BDS, FCPS

Assistant Professor,

Department of Oral Pathology,

Bibi Aseefa Dental College,

Larkana, Sindh

3. BDS, FCPS

Assistant Professor,

Department of Operative Dentistry,

Institute of Dentistry,

Liaquat University of Medical \&

Health Sciences, Jamshoro

4. BDS, MDSc

Assistant Professor of Oral \&

Medicine \& Periodontology

Bibi Aseefa Dental College, Larkana

Correspondence Address:

Dr. Muhammad Ilyas Shaikh

Principal,

Assistant Professor \&

Head of Department of

Oral and Maxillofacial Surgery,

Bibi Aseefa Dental College, Larkana, Sindh.

elya ilyas@yahoo.com

Article received on:

12/07/2014

Accepted for publication:

05/10/2014

Received after proof reading:

$15 / 12 / 2014$

\section{IMPACTED MANDIBULAR THIRD MOLAR SURGERY;} THE ROLE OF DEXAMETHASONE IN POSTOPERATIVE SWELLING AND TRISMUS

\section{Dr. Muhammad Ilyas Shaikh¹, Dr. Safia Khatoon², Dr. Fozia Rajput ${ }^{3}$, Dr. Syed Yousif Ali Shah ${ }^{4}$}

ABSTRACT... Objective: The objective of this study was to evaluate the therapeutic effect of dexamethasone in post-operative edema and trismus after impacted third molar surgery. Materials \& Methods: It was a prospective randomized control study carried in Department of Oral \& Maxillofacial surgery, BADC, Larkana from March 2012 to Feb 2013. Patients age between 20-45 years of either gender; unilateral mandibular impacted third molars (right or left) were included. Patients divided in two groups by using random allocation number. Patients in Group-A were given intramuscular $8 \mathrm{mg}$ dexamethasone 1 hour before surgery and four tablets $(2 \mathrm{mg})$ dexamethasone orally immediate postoperatively and 24 hours after surgery. The facial swelling was checked before surgery, after 24 hours ( $1^{\text {st }}$ day), after 48 hours $\left(2^{\text {nd }}\right.$ day), after 72 hours ( $3^{\text {rd }}$ day) and on $7^{\text {th }}$ postoperative day Inter-incisor distance was checked on every follow up. Data was analyzed by SPSS version 17. Mean and standard deviation was calculated for age and gender. Mean and SD of facial swelling and mouth opening was calculated before extraction, on $1^{\text {st }}, 2^{\text {nd }}, 3^{\text {rd }}$ and on $7^{\text {th }}$ post-operative day in both groups. Results: The dexamethasone group showed significant reduction in swellingcompared with control group at all intervals. Dexamethasone resulted in significantly less trismus than controls on day 2 postoperatively, but there was no significant difference among the groups at 7thday. Conclusions: Dexamethasone is effective in minimizing swelling and trismus after removal of impacted lower third molar and improves the social life of individual.

Key words: $\quad$ Third molar tooth, Dexamethasone, Trismus, Swelling.

Article Citation: Shaikh MI, Khatoon S, Rajput F, Shah SYA. Impacted mandibular third molar surgery; the role of dexamethasone in postoperative swelling and trismus. Professional Med J 2014; 21(6):1272-1278.

\section{INTRODUCTION}

In routine dental care, effective control of postoperative complications plays an important role. The surgical extraction of impacted mandibular third molar is one of the most commonly performed day care procedures in oral and maxillofacial surgery and is associated with varying degrees of postoperative discomfort ${ }^{1}$. As this involves trauma to hard and soft tissue therefore beside severe complications such as dysesthesia, severe infection, mandible fracture and dry socket.Patients frequently complain of pain, swelling and limitation in mouth opening or trismus ${ }^{2}$ and thisinfluence patient's quality of life during the days after surgery. The adverse effects of the third molar surgery on the quality of life have been reported to show a three-fold increase in patients who experience pain, swelling and trismus alone or in combination, compared to those who were asymptomatic ${ }^{3}$.
Surgical trauma in the oral cavity tissue causes injury to the surrounding structures. The greater and extensive tissue injury leads to an increased amount of tissue response and inflammation in the surgical area. Swelling may be particularly significant when the duration of surgery is prolonged and manipulation (like retraction and elevation) of tissues is extensive ${ }^{4}$.

The classic signs of inflammation, which includesDolor, calor, rubor, tumor and Functiolaesa (pain, edema, temperature, erythema, and loss of function), commonly occur after extensiveoral surgical procedures. Theinflammatory process is necessary to track the healing process, but often excessive inflammation causes unnecessary pain, edema,trismusand takes time to repair \&heal. There are many mediators of inflammation, which include prostaglandins (PGs), histamine, bradykinin, and serotonin. Prostaglandin and 
histamine levels are known to become elevated during inflammation ${ }^{5}$. Bradykinin has a wide spectrum of proinflammatoryresponse, including potent pain-producing properties ${ }^{6}$.

Corticosteroids are known to reduce inflammation, fluid transudation and edema ${ }^{7}$. They are the most efficacious anti-inflammatory agents and for this purposecanbeusedinseveraldifferentconditions ${ }^{8}$. Dexamethasone and methylprednisolone have been used extensively in oral and maxillofacial surgery due to their nearly pure glucocorticoid effects, and no mineralocorticoid effects, and the least adverse effects on leukocyte chemotaxis ${ }^{9-10}$. As a protective strategy it is used for restraining postoperative swelling following oral surgical procedures. Being the potent anti-inflammatory agent the dexamethasone is more effective, ${ }^{11}$ andvarious studies have also supported the hypothesis that Dexamethasone are useful in minimizing and preventing post-operative swelling ${ }^{12-13}$.

Some practitioners may consider the use of steroids only as a supplement in patients undergoing extensive oral surgical procedures, but steroids such as dexamethasone can be a valuable tool when performing moderate to moderately severe oral surgical procedures. The use of corticosteroids can decrease the severity of postoperative sequelae in many patients and therefore decreasemorbidity after oral surgery.

The study was aimed to investigate the therapeutic effects of intramuscularinjection of $8 \mathrm{mg}$ dexamethasone, given $1 \mathrm{~h}$ preoperatively and four tablets $(2 \mathrm{mg}$ ) dexamethasone orally immedialte postoperatively and 24 hours after surgery in reducing facial swelling, pain and trismus (mouth opening limitation) and comparethe mean differences between the corticosteroidand controlgroups for early and late postoperative edema and trismus after impacted mandibular third molar surgery.

\section{MATERIALS \& METHODS}

It was a prospective randomized control studycarried in Department of Oral \& Maxillofacial surgery, BibiAseefa Dental College, Larkanafrom March 2012 to February 2013. The InclusionCriteria were the Age between 20-45 years of either gender. Unilateral mandibular impacted third molars (either, right or left).

The Exclusion Criteria were patients already on steroids, with submucous fibrosis, TMJ Dysfunction and limited mouth opening less than $30 \mathrm{~mm}$, clinically significant medical illness/history, patients with pericoronitis, localized infection or any mucosal disease and periapicalpathosis at the time of surgery, drug allergy, chronic use of medicationsthat obscure assessment of the inflammatory response or healing process and pregnant/ lactating woman.

Patients meeting the inclusion criteria were included in the study. The purpose, procedure, risk/benefits of the study was explained to the patients and informed consent was taken regarding their data entry into the study.

Patients enrolled in study were free of pain and other inflammatory sign \&symptoms that included swelling, hyperemia and mucosal changes at the time of surgery.

All the patients were divided into two groups by using random allocation number. Patients in Group-A were given intramuscular $8 \mathrm{mg}$ dexamethasone 1 hour before surgery and four tablets $(2 \mathrm{mg})$ dexamethasone orallyimmedialtely postoperatively and 24 hours after surgery. Additionally Antibiotic Amoxicillin and Analgesic Naproxen Sodium were advised post operatively. While in (Control) Group B, Only Antibiotic Amoxicillin and Analgesic Naproxen Sodium were advised post operatively.

After taking detailed history and thorough clinical examination periapical $\mathrm{x}$-rays were taken for all patients and panoramic radiograph (OPG) in few patients.

Patients were instructed for chlorhexidine $0.2 \%$ rinses, before local anesthesia. Surgery was done in smooth environment and surgical procedure 
was done to remove third molars.

The facial swelling was checked before surgery (as base line measurement), after 24 hours (1stday), after 48hours (2ndday), after 72 hours (3rd day)and on 7thpostoperative periods and inter-incisor distance on every follow up.

The facial swelling as linear measurement was evaluated by measuring the distance from lateral canthus of the eye to the angle of the mandible and from corner of the mouth to the tragus of ear with the help of flexible measuring tape in millimeters $(\mathrm{mm})$. The baseline measurement was considered the sum of the two values ( $\mathrm{mm}$ ).

Inter-incisor distance was measured by verniercalliper to record the difference in maximum mouth opening before and after surgical procedure on every follow up.

Data were analyzed by SPSS version 17. Mean and standard deviation was calculated for age and gender. Impacted mandibular3rd molars were classified according to their angulation, and percentage was calculated. Mean and SD of facial swelling and mouth opening was calculated before extraction, on 1st, 2nd, 3rd and on7thpostoperative day in both groups.

\section{RESULTS}

A total of 80 individuals were enrolled in this study, with mandibular impacted third molars. There were 54(67.5\%) males and 26(32.5\%) females (Fig-1). The mean age was $27.2 \pm 6.157$ years. Individuals were divided into two groups by using random allocation number. In group $A$ (with steroids) and group B (control) there were 40 patients each. Group A consist of 28 male and 12 female patients, while group B consist of 26 male and 14 female patients.(Table-I)

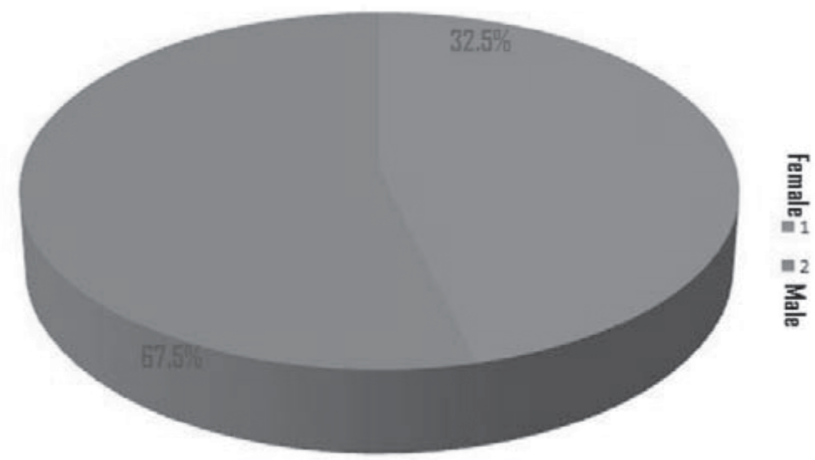

Fig-1. Gender Distribution

\begin{tabular}{|c|c|c|c|}
\hline $\begin{array}{c}\text { Third molar } \\
\text { Angulation }\end{array}$ & Group A & Group B & Total \\
\hline Mesioangular & 23 & 21 & $44(55 \%)$ \\
\hline Vertical & 12 & 13 & $25(31.25 \%)$ \\
\hline Distoangular & 3 & 4 & $07(8.75 \%)$ \\
\hline Horizontal & 2 & 2 & $04(5 \%)$ \\
\hline Total & 40 & 40 & $80(100.0 \%)$ \\
\hline
\end{tabular}

Table-II. Cases Distribution according to Third molar Angulation

The radiographic analysis was taken for all the patients, which determines the majority of the impacted teeth were in mesioangular position account for $45 \%$ of cases, followed by vertical, distoangular and horizontal impaction.(Table-II)

Facial swelling was significantly reduced in steroid group. On 1st and 2ndpost-operative day significant difference was found between the dexamethasone and control groups in facial swelling measurement. Dexamethasone significantly reduced postoperative facial swelling on 3rd postoperative day (Fig-2). On last follow up visit the 7th post-operative day, facial swelling has no significant differences in both groups. (Table-III)

\begin{tabular}{|c|c|c|c|c|}
\hline Sex & Group A Steroid group & Group B Control group & \multicolumn{1}{|c|}{ Total } & Mean age \& STD \\
\hline Male & 2827 & 26 & $54(67.5 \%)$ & $27.9 \pm 6.500$ \\
\hline Female & 12 & 14 & $26(32.5 \%)$ & $25.7 \pm 5.179$ \\
\hline Total & 40 & 40 & $80 \%)$ & $27.2 \pm 6.157$ \\
\hline
\end{tabular}




\begin{tabular}{|c|c|c|}
\hline \multirow{2}{*}{ Swelling } & Group A & Group B \\
\hline Preoperative Baseline Measurement & Mean (mm) STD & Mean (mm) STD \\
\hline 1st Post op day & $2.62 \pm 0.8032$ & $2.54 \pm 0.63075$ \\
\hline 2nd Post op day & $4.2 \pm 0.7365$ & $5.70 \pm 0.78066$ \\
\hline Diff bwPreop and after 48 hours & $5.4 \pm 0.7264$ & $6.35 \pm 0.669438$ \\
\hline 3rd Post op day & $2.78 \pm 1.965757$ & $3.81 \pm 2.96$ \\
\hline 7th Post op day & $4.78 \pm 0.7075$ & $6.0 \pm 0.625505$ \\
\hline Diff bwPreop and Postop 7th & $2.84 \pm 0.7782$ & $2.92 \pm 0.763926$ \\
\hline Table-III. Measurement of Facial Swellings in both groups after mandibular third molar extraction (in mm) \\
\hline
\end{tabular}

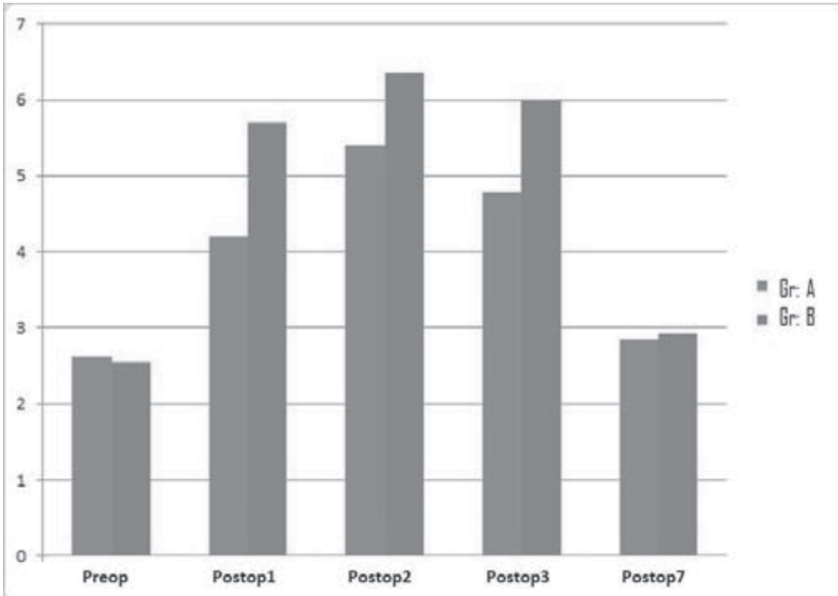

Fig-2. Facial Swelling Preop and Post operative in both groups

Limited mouth opening expressed as the reduction (in $\mathrm{mm}$ ) in the interincisor distance of each individual comparedpre and postoperatively. The difference in the maximal interincisor distance was assessed on $1^{\text {st }}, 2^{\text {nd }}, 3^{\text {rd }}$ and $7^{\text {th }}$ post-operative day. (Fig 3)

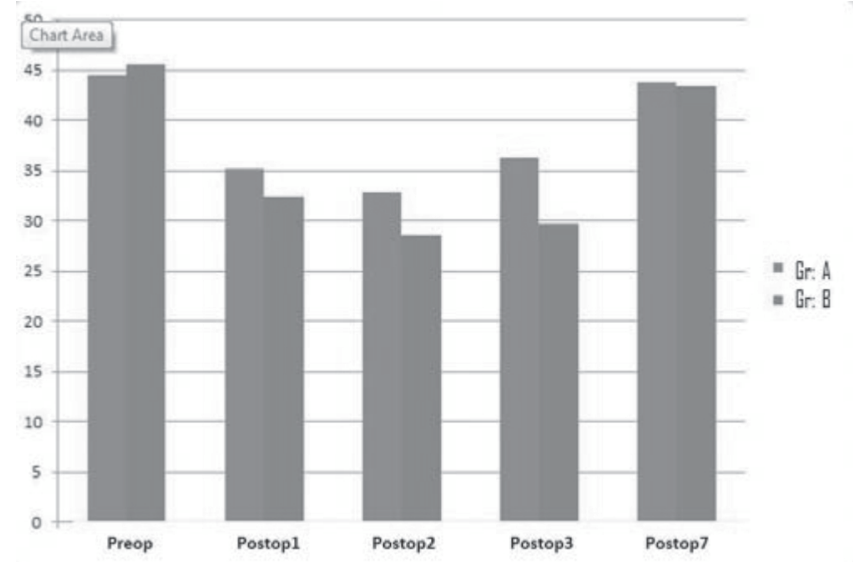

Fig-3. TrismusPreop and Post operative in both groups

Trismuswas worse on $2^{\text {nd }}$ post-operative day in control group and had significant reduction in mouth opening. While comparing to control group, steroid group had significant differences noticed in mouth opening. Mouth opening gradually improved thereafter in both groups and had almost normal mouth opening in steroid group as compared to control group, which had still limited mouth opening. (Table-IV).

\begin{tabular}{|c|c|c|}
\hline & Group A & Group B \\
\hline & Mean STD & Mean STD \\
\hline Preoperative mouth opening & $44.55 \pm 3.686079$ & $35.65 \pm 3.453352$ \\
\hline 1st Post op day & $35.22 \pm 3.25409$ & $32.42 \pm 2.706947$ \\
\hline 2nd Post op day & $32.87 \pm 2.533747$ & $28.6 \pm 3.1849$ \\
\hline Diff bwPreop and after 48 hours & $11.68 \pm 8.255472$ & $17.05 \pm 12.05617$ \\
\hline 3rd Post op day & $36.32 \pm 2.702207$ & $29.62 \pm 3.010132$ \\
\hline 7th Post op day & $43.77 \pm 3.32425$ & $43.37 \pm 3.333494$ \\
\hline Diff bwPreop and Postop 7th & $0.78 \pm 0.548008$ & $2.28 \pm 1.608668$ \\
\hline Table-IV. Mean difference in mouth opening of both groups after mandibular third molar extraction (in mm)
\end{tabular}


Steroid group has excellent results regarding the postoperative complaints. Approximately $80 \%$ of postoperative measurements (in relation to swelling and mouth opening) had returned to the preoperative values, by follow up visit on 7 th post-operative day in control group, which is in contrast with $100 \%$ in steroid group.

\section{DISCUSSION}

Surgical extraction of the impacted third molar is the most common and perhaps the most discussed \& challenging surgical procedure in Oral and Maxillofacial surgery. Usually a large population of individuals may have one or more impactions and mandibular third molar impactions are even up to the $98 \%$ of all impactions.

Mean age remains the $27.2 \pm 6.157$ years in our study, with third decade the predominant age group, which is similar with the other studies ${ }^{13,14,15}$. Thus almost more than two third of the patients were in the third decade of their lives. This decrease in number of impactions with increasing age is due to asymptomatic nature of their impacted third molar teeth and less awareness of individuals regarding the complications. This would be due to the fact that asymptomatic tooth and lack of awareness regarding oral health leads to unnecessary delay in treatment. According to gender distribution, impaction of mandibular third molar was common in males; similar results are with other studies ${ }^{13,15,16}$. Where as many studies $^{14,17}$ also have shown female dominance in patients with third molar impactions.

Wehavefound increased mesioangularpositioning of the third molar impactions (55\%). Following this vertical impactions $(31.25 \%)$ were the second most common impactions, then distoangular $(8.75 \%)$ \& horizontal $(5 \%)$ subsequently. Like others studies of this region ${ }^{13,16,17}$ and other countries 14,18,19mesioangular impaction remained the most common impacted third molar among all positions.

Postoperative swelling and trismus is considered a common and unavoidable event after surgery of impacted third molar and may cause facial asymmetry, marked trismus and unbearable pain. In fact it affects, only for a few days, the social and working life of the individual, despite this all reasonable steps should be taken to minimize these consequences.

Steroids undoubtedly decreased post-operative swelling. Many authors have advocated the use of corticosteroids to limit postoperative edema due to their suppressive action on transudation. Dexamethasone hasalonger duration of actionand is more efficacious compared to other steroids. It is one of the most potent anti-inflammatory drugs and for this reason Dexamethasone was given $8 \mathrm{mg}$ $\mathrm{IM}, 1 \mathrm{hr}$ before surgery and $2 \mathrm{mg}$ (4tablets) orally immediate postoperatively and after 24 hours of surgery. The most significant part of the study was the inspection and evaluation of swelling. We have used flexible measurement tape in order to achieve accurate measurements of facial swelling and patients were seen pre-operatively, the 1st, 2nd, 3rd and 7th postoperative days respectively. On the second postoperative day, where edema was at higher level but comparing to control group, steroid group had marked difference in size and further reducing in size on third post-operative day effectively. Dexamethasone effectively decreased \& control the size of swelling, as compared to the control group and was almost nil on the last follow up visit.

These findings are similar to those described in a previous studies ${ }^{13,16,17}$, that dexamethasone decreased postoperative facial swelling and in 2008, FILHO et $\mathrm{al}^{21}$ also concluded that decrease in facial swelling on day 2 after operation using 4 and $8 \mathrm{mg}$ dexamethasone, given preoperatively; 8 $\mathrm{mg}$ was more effective than $4 \mathrm{mg}$ dexamethasone.

Another quiet common postoperative sequel of lower third molar surgery is trismus, which is often secondary to surgical trauma, masticatory muscle spasm and inflammation of surrounding tissues. It is also due to postoperative swelling, lead to compression of nervous structures and producing mild to severe pain. The patients may feel jaw stiffness with difficulty to eat normally postoperatively22. 
In this study, steroid group had significant differences noticed in mouth opening. On day 2, limited mouth opening was very severe i.e about $28.6 \mathrm{~mm} \pm 3.1849$ in control group while 32.87 $\mathrm{mm} \pm 2.533747 \mathrm{~mm}$ in steroid groups. The mean difference noted was $11.68 \pm 8.255472$ reduction of mouth opening in steroid group and 17.05 \pm 12.05617 reductions in mouth opening in control group. This difference indicates the positive response of steroid therapy. Mouth opening gradually improved thereafter in both groups and had almost normal on 7TH postoperative day in steroid group as compared to control group, which had still limited mouth opening. (Table IV)

Similarly in a study conducted by HiraAyazet all, ${ }^{23}$ they had $81.1 \%$ of subjects with severe Trismus on the 3rd postoperative day. Majority of subjects regained their normal mouth opening by the 7th postoperative day which is again similar to our findings.

In our study we noticed that steroid group has excellent results regarding the postoperative complaints. Approximately $80 \%$ of postoperative measurements (in relation to swelling and mouth opening) had returned to the preoperative values, by follow up visit on 7th post-operative day in control group, which is in contrast with $100 \%$ in steroid group.

\section{CONCLUSIONS}

The findings of this study suggest that preoperative and postoperative administration of dexamethasone has an excellent results regarding control of postoperative early and late edema and trismus compared with controls by comparing the mean differences between the dexamethasone and control group.

Copyright@ 5 Oct, 2014.

\section{REFERENCES}

1. Nazar MN, Puthiriraj V. Analgesics Following Mandibular Third Molar Surgery. IJPCR, 2014:6:13-19.

2. Khan A, Khitab U, Khan MT. Impacted Mandibular Third molars: Pattern of presentation and post-operative complications. PODJ 2010; 2:307-12.
3. McGrath C, Comfort MB, Lo EC, Luo Y. Changes in quality of life following third molar surgery- the immediate postoperative period. $\mathrm{Br}$ Dent $\mathrm{J}$ 2003; 194:265-8.

4. Kim K, Brar P, Jakubowski J, et al: The use of corticosteroids and nonsteroidalantiinflammatory medication for the management of pain and inflammation after third molar surgery: a review of the literature. Oral Surg Oral Med Oral Pathol Oral RadiolEndod 2009;107:630-640.

5. Gersema L, Baker K. Use of corticosteroids in oral surgery. J Oral and Maxillofac 1992;50:270-7.

6. Hargreaves KM, Costello A. Glucocorticoids suppress levels of immunoreactivebradykinin in inflammed tissue as evaluated by microdialysis probes. ClinPharmacolTher 1990;48:168-78.

7. Beirne OR. Evaluation dexamethasone for reduction of postsurgical sequele of third molar removal. J Oral MaxillofacSurg 1992;50:1182-3.

8. Holte $\mathrm{K}$, Kehlet $\mathrm{H}$. Perioperative single-dose glucocorticoid administration: Pathophysiologic effects and clinical implications. J Am CollSurg 2002;195:694-711.

9. Hupp RJ. Principles of management of impacted teeth. In: Contemporary Oral and Maxillofacial Surgery. 5th ed. St Louis: CV Mosby; 2008;153-78.

10. Montgomery MT, Hogg JP, Roberts DL, Redding SW. The use of glucocorticosteroids to lessen the inflammatorysequelae following third molar surgery. J Oral Maxillofac Surg. 1990; 48:179.

11. de Sousa Santos JAS, et al. Comparative study of tramadol combined with dexamethasone and diclofenac sodium in third-molar surgery. J CraniomaxillofacSurg 2012;40: 694-700.

12. Mushtaq M, Khan HA, Hussain A. Effect of dexamethasone on swelling, pain and trismus following third molar surgery. Gomal Journal of Medical Sciences. 2011;9:74-77.

13. Channar KA et al. Dexamethasone in control of postoperative sequalae after extraction of mandibular impacted third molars. MC 2013;19:63-66.

14. Jaffar RO, Tin-Oo. Impacted mandibular third molars among patients attending Hospital UniversitiSains Malaysia. Archives of Orofacial Sciences 2009;4:7-12.

15. Blondeau F, Daniel NG. Extraction of impacted mandibular third molars: postoperative complications and their risk factors. J Can Dent Assoc 2007;73:325- 
31.

16. Amanat N, Mirza D, Rizvi KF. Pattern of third molar impaction: frequency and types among patients attending urban teaching hospital of Karachi. PODJ 2014;34:34-37.

17. Khan A, Khitab U, Khan MT. Impacted mandibular third molars: pattern of presentation and postoperative complications. PODJ 2010; 30:307-312.

18. Quek SL, Tay CK, Tay KH, Toh SL, Lim KC. Pattern of third molar impaction in a Singapore Chinese population; a retrospective radiographic survey. Int $\mathrm{J}$ Oral MaxillofacSurg 2003; 32: 548-52.

19. Unwerawattana W. Common symptoms and type of impacted molar tooth in King Chulalongkorn Memorial Hospital. J Med Assoc Thai 2006; 89: 134-39.
20. Alexander RE, Throndson RR. A review of perioperative corticosteriod use in dentoalveolar surgery. Oral Surg Oral Med Oral Pathol Oral RadiolEndod 2000;90:40615.

21. Filho JRL, Maurette PE, Allais M, Cotinho M, Fernandes C. Clinical comparative study of the effectiveness of two dosages of dexamethasone to control post operative swelling, trismus and pain after the surgical extraction of mandibular impacted third molars. Med Oral Patol Oral Cir Bucal 2008;13:129-32.

22. TunzunerOncul AM et al. Postoperative Analgesia in Impacted Third Molar Surgery: The Role of Preoperative Diclofenac Sodium, Paracetamol and Lornoxicam. Med PrincPract 2011;20:470-476.

23. Ayaz H, Atta-UR-Rehman, Fahimuddin. Postoperative complications associated with impacted mandibular third molar removal. PODJ 2012; 32;389-392.

\section{Good players inspire themselves great players inspire others.}

\section{Unknown}

